\title{
Detection and monitoring of serum p53 antibodies in patients with colorectal cancer
}

P Hammel, B Boissier, M-T Chaumette, P Piedbois, N Rotman, J-C Kouyoumdjian, R Lubin, J-C Delchier, T Soussi

\begin{abstract}
Background-Detection of p53 antibodies in serum might be an effective indirect procedure to detect alterations of the p53 gene.
\end{abstract}

Aims-To assess the prevalence and the variation under treatment of p53 antibodies in patients with colorectal cancer.

Patients and methods-Fifty four patients with colorectal cancer (26 men and 28 women, mean age 65 , range 33-90 years) and 24 patients with non-malignant digestive disease were tested for p53 antibodies by enzyme linked immunosorbent assay (ELISA), and for the carcinoembryonic antigen and carbohydrate antigen 19.9. Immunohistochemical detection of p53 protein tumour overexpression was performed in 38 cases.

Results-Fourteen patients $(26 \%)$ with colorectal cancer but none of those with non-malignant disease displayed p53 antibodies. Overexpression of p53 was shown by immunohistochemistry in 22 patients $(58 \%), 10$ of whom also had p53 antibodies. The antibodies were present in four patients with high carcinoembryonic antigen and three patients with high carbohydrate antigen 19.9 concentrations, but also in 10 patients $(33.3 \%)$ with normal values of these markers. The ratio of p53 antibodies decreased in 11 of 13 patients after tumour resection. In two patients variations in p53 ratio strongly correlated with tumour relapse or progression. bodies constitutes a useful technique for assessing alterations in p53 and may help physicians to follow up patients with colorectal cancer.

(Gut 1997; 40: 356-361)

Keywords: p53 gene, p53 antibodies, colorectal cancer, carcinoembryonic antigen, carbohydrate antigen 19.9.

Service de Chirurgie Digestive, Hôpital

Henri Mondor, 94010

Créteil, France

N Rotman

Unité 301 INSERM, Institut de Génétique Moléculaire, 75010

Paris, France

R Lubin

T Soussi

Correspondence to:

Dr P Hammel,

Service de Gastroentérologie

Service de Gastroenter

Hopital Beaujon, 100
boulevard Leclerc, 92110

boulevard Lecle

Accepted for publication

31 October 1996

Inactivation of the p53 tumour suppressor gene is the most common genetic alteration in human cancers. ${ }^{12}$ This alteration is usually caused by missense point mutations of the gene. Sometimes, inactivation of the p53 protein may occur through complex formation with cellular proteins. ${ }^{3}$ Alterations in p53 have prognostic value in colon, breast, and gastric cancers and so their recognition may be important for clinicians. ${ }^{4-7}$ Although the most accurate procedure for analysis of p53 status is DNA sequencing, this technique is not feasible
Conclusion-Testing for serum p53 anti-

on a routine clinical basis. Because most mutations modify the confirmation and the $\vec{\circ}$ stability of the p53 protein and lead to its accumulation in the nucleus of tumour cells, $\vec{\omega}$ there has been intensive investigation of screening p53 alterations by immunohistochemical analysis. ${ }^{8}$ A third approach for the ${ }^{\circ}$ diagnosis of $\mathrm{p} 53$ alterations which has recently been developed consists of the detection of $\mathrm{p} 53 \mathrm{~W}$ antibodies (p53-Abs) in the serum of patients? affected by a wide variety of cancers. ${ }^{9-16} \mathrm{The}_{-}^{\mathrm{S}}$ presence of these antibodies usually correlates 3 with the accumulation of the $\mathrm{p} 53$ protein in tumour cells, but there are some excep-ร tions. ${ }^{17}{ }^{18}$ p53-Abs belong to $\operatorname{IgG}_{1}$ or $\operatorname{IgG}_{2} \overrightarrow{0}$ classes, suggesting that they correspond to a $v$ secondary immune response induced by two immunodominant regions localised in the carboxyterminus and the aminoterminus of the $\bar{\partial}$ p53 protein outside the central mutationalo hotspot region. ${ }^{19-21} \mathrm{~A}$ recent study has clearly足 shown that these antibodies are directed $\overrightarrow{\vec{F}}$ toward human p53 either in wild type or 3 mutant form. ${ }^{22}$ Serological analysis of $\mathrm{p} 53$ 궁 alterations has several advantages: (1) it iș. relatively easy to perform and to repeat; ino addition, the stability of p53-Abs allows retrospective studies; (2) it does not require 3 tumour material; (3) it is of potential interesto for monitoring patients with cancer.

Colorectal cancer is the most commono gastrointestinal malignancy worldwide, and? alterations of the p53 gene are found in abouto $60 \%$ of these cases. ${ }^{24}$ To the best of our knowledge, $\mathrm{p} 53-\mathrm{Ab}$ expression in colorectalos cancer has not been effectively studied. ${ }^{15}$ N

The purpose of this prospective study was tot assess: (1) the prevalence of p53-Abs ing colorectal cancer and to compare this with theo widely used tumour markers the carcinoembryonic antigen (CEA) and the carbohydrate antigen $(\mathrm{Ca}) 19.9$; (2) the specificity of p53-Ab testing in patients with various digestive non- $\frac{\text { Dे }}{\mathrm{D}}$ malignant diseases; (3) the potential value of $\mathrm{p} 53-\mathrm{Ab}$ monitoring for the management of patients with colorectal cancer. 
Tumours

According to the Dukes' classification, ${ }^{25} 10$ patients were stage A, 19 were stage $B$, and 25 were stage $C$ (nine with liver metastases). The site of the primary tumour was the rectum in 14 cases, the left colon in 26 cases, and the right colon in 14 cases. Patients who had locally advanced rectal cancer (Dukes' B or C) received preoperative irradiation (40 Gy). All patients studied underwent resection of the colorectal tumour, including those with distant metastases.

\section{Serum samples}

Serum samples of the 54 patients with colorectal cancer were collected after diagnosis but before treatment during routine blood sampling. Serum samples of 24 patients with various non-malignant digestive diseases (benign colonic adenoma, familial adenomatous polyposis, Peutz-Jeghers syndrome, gastritis, alcoholic cirrhosis, and chronic viral hepatitis) were also collected. Patients were informed and gave their consent for the study. Whole blood was centrifuged at $3000 \mathrm{rpm}$ for 15 minutes and the supernatant was stored at $-80^{\circ} \mathrm{C}$ until use.

Enzyme linked immunosorbent assay (ELISA)

Enzyme linked immunosorbent assay (ELISA) for the detection of p53-Abs in serum has been previously described. ${ }^{22}$ Briefly, we have developed a highly specific ELISA by testing all samples with a two antigen preparation. The first preparation contained the relevant antigen (purified p53 protein) and in the second the antigen was omitted. All results have been expressed as the ratio between the number of wells containing the p53 antigen and the corresponding wells without. We have previously reported that samples of blood donors (200) and patients with various carcinomas (more than 1000) indicated that a ratio higher than $2 \cdot 0$ confirms the presence of $\mathrm{p} 53-\mathrm{Ab}$. All analyses were performed in duplicate.

\section{Carcinoembryonic antigen and carbohydrate antigen 19.9}

The antigens CEA and $\mathrm{Ca} 19.9$ were tested with commercially available radioimmunoassay kits (Boehringer, Mannheim, Germany). Cut off concentrations of $5 \mathrm{ng} / \mathrm{ml}$ and 37 $\mathrm{U} / \mathrm{ml}$ respectively, were recommended by the manufacturers.

\section{Immunohistochemistry}

Immunostaining for p53 was performed on 3 $\mu \mathrm{m}$ deparaffinised sections using the monoclonal antibody anti-p53 DO7 (Dakopatts A/S, Glostrup, Denmark) which recognises, on both wild type and mutant forms of the proteins, an epitope in the $\mathrm{N}$-terminal part of the human p53 protein between amino acids 35 and 45 . A preliminary treatment was performed by incubating the deparaffinised slides twice for five minutes at $650 \mathrm{~W}$ in citrate buffer $(\mathrm{pH} \mathrm{7 \cdot 6)}$ in a microwave oven. Sections were then left at room temperature for 90 minutes before incubation with the $\mathrm{DO} 7$ antibody at a concentration of $1: 50$ for 30 minutes.

The pathologist who performed the immunohistochemical analysis was not informed of the patients' p53-Ab status.

\section{Statistical analysis}

Comparisons of the patients' clinical status (age, sex, localisation of tumour, stage) according to $\mathrm{p} 53-\mathrm{Ab}$ statur were performed by a logistic regression test.

\section{Results}

\section{Detection of $p 53-A b$ in serum}

Among the 54 patients with colorectal cancer, $14(26 \%)$ had p53-Abs at a ratio varying from $2 \cdot 1$ to 57 . By contrast, all 24 patients with nonmalignant digestive disease had a $\mathrm{p} 53 /$ control ratio lower than $2 \cdot 0$. Figure 1 shows these results. The Table describes the clinical characteristics, treatment, and follow up of patients with p53-Abs.

Patients with p53-Abs were significantly younger than patients without p53-Abs (54 v 66 years, $\mathrm{p}<0.03$ ) but other variables (sex, localisation of tumour, stage) were not associated with the presence of p53-Ab.

\section{Detection of p53 overexpression by immunohistochemistry}

Overexpression of the p53 protein was detected by immunohistochemistry in 22 out of 38 patients $(58 \%)$ for whom results were available. Ten of these 22 patients ( $45 \%)$ had p53-Abs in serum. The level of p53 expression by immunohistochemistry was similar in patients with or without p53-Abs. On the other hand, one stage $B$, and one stage $C$ patient displayed p53-Abs in the absence of any detectable p53 overexpression in several tumour samples studied by immunohistochemistry.

\section{$C E A$ and $C A 19.9$}

Values for CEA were above normal in 20 out

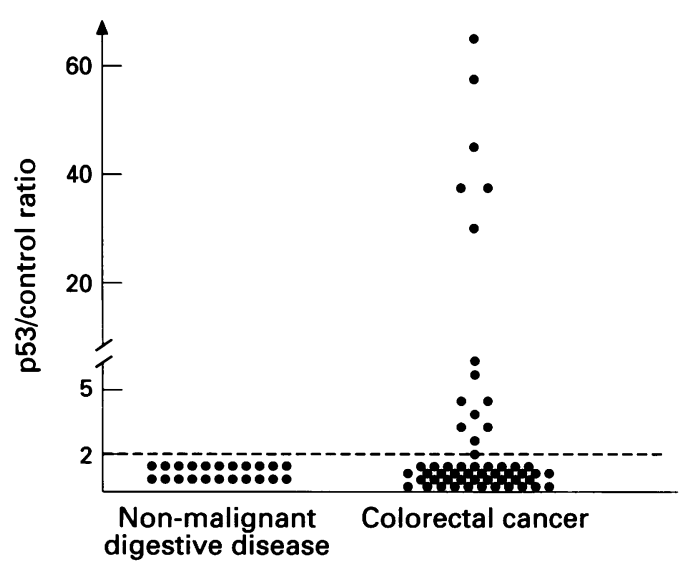

Figure 1: p53 Antibodies in 54 patients with colorectal cancer and in 24 patients with non-malignant digestive disease. 
of 54 patients $(37 \%)$ tested before treatment. Four of these patients also had high p53-Ab concentrations in serum. Values for $\mathrm{Ca} 19.9$ were above normal in 15 out of 54 patients $(28 \%)$ tested before treatment. Three of these patients also had high p53-Ab concentrations in serum. Among the 30 patients with normal $\mathrm{CEA}$ and $\mathrm{Ca} 19.9$ values, 10 (33.3\%) had high p53-Ab concentrations. By contrast, all 24 patients with non-malignant digestive disease had normal CEA and Ca $19 \cdot 9$ values.

\section{Monitoring of p53-Abs}

Twelve patients with p53-Abs were tested several times to identify the variation of ratio within the follow up period. The Table gives the results. Five of the eight patients $(\mathrm{CC} 1$, CC21, CC24, CC38, CC47), who were tested within the first month after tumour resection, showed a $\geq 25 \%$ drop in the $\mathrm{p} 53-\mathrm{Ab}$ ratio. Three of the eight patients (CC3, CC34, CC38) tested one year or more after tumour resection, returned to normal p53- $\mathrm{Ab}$ ratios. Three other patients (CC6, CC30, CC49) still had $\mathrm{p} 53-\mathrm{Ab}$ but showed a considerable decrease (of $30 \%, 79 \%$ and $72 \%$ respectively) in concentrations (Table). These patients were asymptomatic 23, 21, and nine months after tumour resection, respectively. Patient CC49 is described in detail.

Patient CC49-This 33 year old woman had a history of $\geq 10$ years of ulcerous pancolitis. In March 1994, multiple biopsies throughout the colon were performed during a systematic complete colonoscopy. Several foci of severe dysplasia were seen at histological examination of the left colon samples. The patient underwent total colectomy with ileo-anal anastomosis. Examination of the resected colon confirmed the presence of several scattered areas of high grade dysplasia. Moreover, a focal $\left(\leq 1 \mathrm{~cm}^{2}\right)$ cancer with transparietal involvement and a single juxtatumorous metastatic lymph node 5 $\mathrm{mm}$ in diameter was discovered. The patient was diagnosed with a Dukes' $\mathrm{C}$ colon cancer. Overexpression of p53 was demonstrated not only at the cancer site but also on the adjacent non-tumorous mucosa. The p53 ratio decreased after tumour resection (Table). Concentrations of p53-Abs are still being monitored.
In two patients, a postoperative increase in p53-Ab concentrations was seen when tumour relapse or progression was diagnosed. Both findings are described in detail below (patients CC24 and CC37).

Patient CC24-This 44 year old female patient was operated on in March 1994 for a Dukes' B adenocarcinoma involving the sigmoid colon. This patient received chemotherapy consisting $\underset{\vec{S}}{\stackrel{\vec{S}}{+}}$ of a combination of 5 fluorouracil and folinic acid (nine courses) within the 10 months after surgery. Before treatment, she had high serum $\frac{\bar{\omega}}{\vec{D}}$ concentrations of p53-Abs (ratio 58.1). Im- $\cong$ munohistochemical analysis of the resected specimen showed overexpression of the p53 $\vec{\circ}$ protein. Preoperative serum values for CEA and $\mathrm{Ca} 19.9$ were normal; p53-Abs fell within $\vec{\omega}$ the first months after tumour resection and remained stable at a fairly high concentration (ratios of between 13 and 18). In June 1995, $\overrightarrow{0}$ the p53-Ab ratio increased to 31.8 but the patient remained asymptomatic. A colorectal perianastomosis tumour relapse was suspected by CT and confirmed by endo-ultrasonography. The patient underwent laparotomy for com- $\vec{z}$ plete resection of a tumorous mass measuring $25 \times 50 \mathrm{~mm}$ in diameter. There were no peritumorous metastatic nodes nor other $\vec{\bullet}$ patent tumour localisation in the abdomen. $\stackrel{?}{v}$ The p53-Ab ratio decreased once again after this second operation (Fig 2). Immunohistochemistry of the resected specimen also disclosed p53 overexpression. In April 1996, the patient suddenly died of pulmonary embolism although her $\mathrm{p} 53-\mathrm{Ab}$ concentrations $\overrightarrow{\vec{A}}$

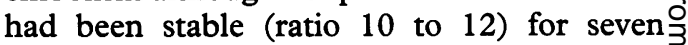
months. A postmortem examination was not? done.

Patient CC37-This 37 year old female patiento had a Dukes' C rectal adenocarcinoma which was diagnosed at the end of October 1994. The 3 . patient had high concentrations of p53-Abs in serum (ratio 65.7), but CEA and $\mathrm{Ca} 19.9$ 을 concentrations were normal. Overexpression ${ }_{\circ}$ of p53 was shown by immunohistochemical analysis performed on biopsy samples obtainedo before treatment. Radiotherapy (45 Gy) was given preoperatively. In January 1995, she underwent tumour resection followed by distals colorectal anastomosis and then received N chemotherapy consisting of a combination of

Clinical characteristics, treatment, and follow up of the 14 patients with colorectal cancer and $p 53$ antibodies

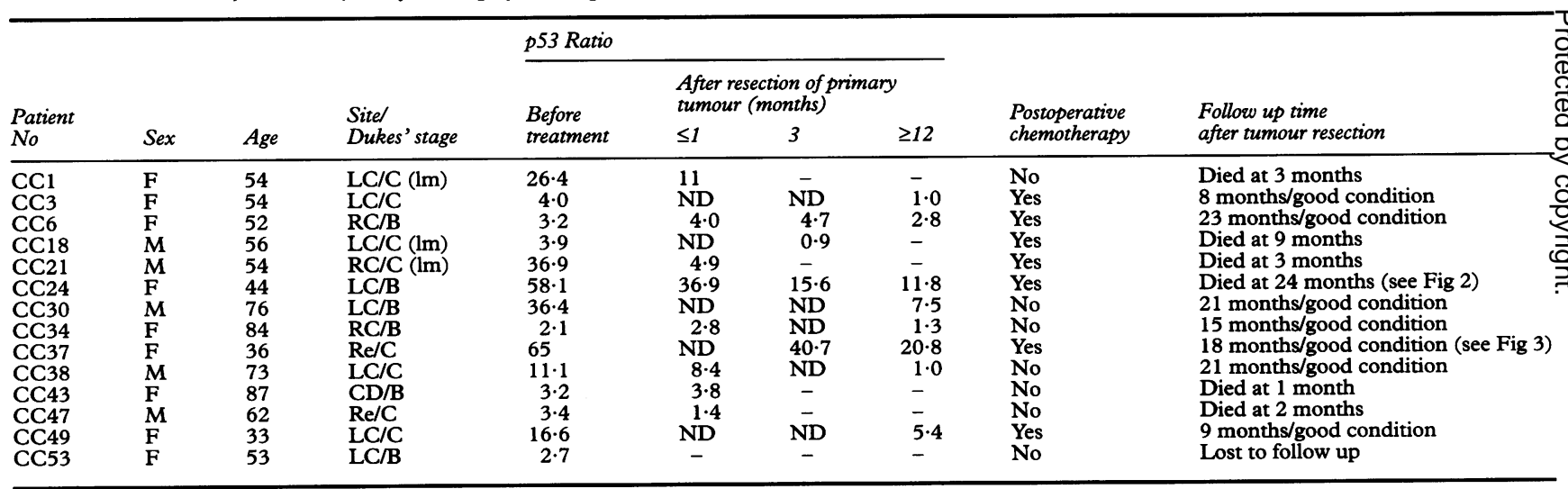




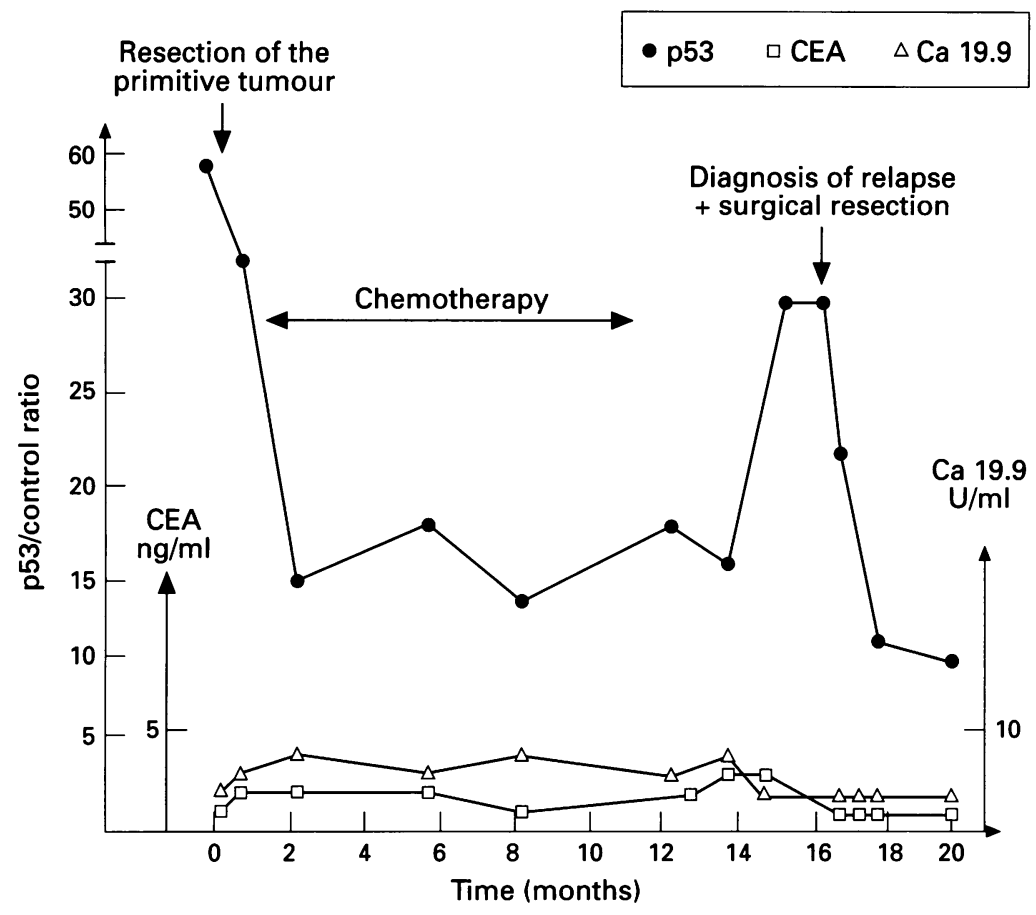

Figure 2: Evolution of p53 antibodies, CEA, and Ca 19.9 serum values in patient CC24.

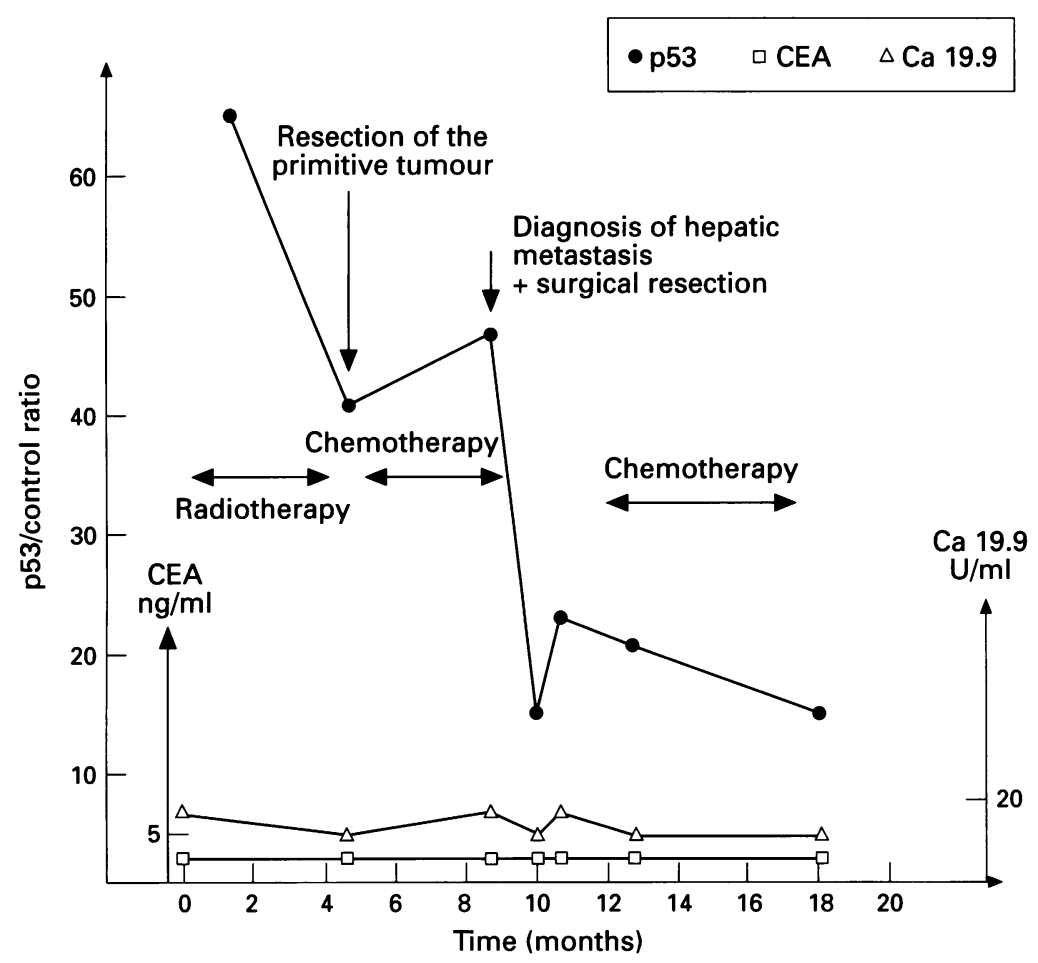

Figure 3: Evolution of p53 antibodies, CEA, and Ca 19.9 serum values in patient CC37.

5-fluorouracil and folinic acid. A pronounced decrease in $\mathrm{p} 53-\mathrm{Ab}$ concentrations was found after tumour resection (Fig 3). In May 1995, the p53 ratio again increased but the patient remained asymptomatic. Hepatic ultrasonography showed a single hepatic metastasis located in the left lobe $(3 \mathrm{~cm}$ in diameter) and the patient underwent segmental hepatic resection. There were no other apparent abdominal tumours. Immunohistochemistry on the resected metastasis disclosed p53 overexpression as in the rectal tumour. Concentrations of $\mathrm{p} 53$-Abs decreased after the second operation (Fig 3). The patient remains asymptomatic eight months after hepatic resection whereas the $\mathrm{p} 53-\mathrm{Ab}$ concentration is still high (ratio 17). Concentrations of p53-Abs are still being monitored.

\section{Discussion}

This work represents the largest published series examining $\mathrm{p} 53-\mathrm{Ab}$ response in colorectal cancer. We found that $26 \%$ of the patients with colorectal cancer had p53-Abs. This is the highest percentage of p53-Abs reported in patients with cancer compared with those reported for lung $(24 \%)$, pancreatic $(19 \%)$, bladder $(17 \%)$ and breast $(13 \%)$ cancers. ${ }^{22}$ As the prevalence of p53-Abs seems to be clearly proportional to the occurrence of $\mathrm{p} 53$ mutations, ${ }^{20} 22$ it is not surprising to find similar prevalences of $\mathrm{p} 53-\mathrm{Abs}$ in colorectal and lung cancer, two diseases with a $60 \%$ rate of $\mathrm{p} 53$ mutations. In a study published by Angelopoulou et al,,$^{15}$ a $15 \%$ prevalence of p53-Abs in patients with colon cancer was reported. The lower rate of $\mathrm{p} 53-\mathrm{Abs}$ in this series could be due to patient selection bias or because of the use of different assays. This emphasises the importance of standardised techniques and methods for recording p53 antibody titres for comparative studies. In the present series, only 10 of the 22 patients who showed accumulation of the p53 protein by immunohistochemical analysis developed p53-Abs. In this study, as in a study by Winter et $a l{ }^{13}$ the level of $\mathrm{p} 53$ expression by immunohistochemistry did not seem to correlate with the $\mathrm{p} 53-\mathrm{Ab}$ production. It is not clear why many tumours with $\mathrm{p} 53$ mutations or protein overexpression are not immunogenic. It is clear that the stabilisation and accumulation of mutant p53 proteins are prerequisites for p53-Ab production. ${ }^{20}$ Although it has been shown that p53 mutations leading to the formation of complexes between p53 and a 70 $\mathrm{kDa}$ heat shock protein are found in antibody eliciting tumours, ${ }^{11}$ other studies suggest that p53-Ab expression is not related to specific mutations of the p53 gene. ${ }^{1326}$ The influence of other variables in the development of p53-Abs such as tumour stage, the immune status of patients, or major histocompatibility merits further investigation. ${ }^{1}$

Two patients in the present series showed p53-Abs without evidence of immunohistochemical overexpression of $\mathrm{p} 53$. This has been previously described, ${ }^{17} 1820$ and several explanations are possible: (1) immunohistochemistry is highly dependent on sampling when the tumour is heterogeneous. By contrast, p53-Ab detection represents a more global approach to detect $\mathrm{p} 53$ alterations and is not dependent on a sample; (2) frameshift mutations of the p53 gene may lead to an immune response without p53 protein accumulation through modifications of p53 antigen processing or its presentation to the immune system ${ }^{17}$; (3) the presence of another occult p53-Ab eliciting cancer cannot be excluded.

In the present study, p53-Ab detection was $100 \%$ specific for diagnosis of cancer as none of the patients with various non-malignant 
digestive diseases displayed these antibodies. This finding is supported by previous reports which show that p53-Abs were specifically encountered in patients with cancer. ${ }^{10} 15$ In this series, there was also no false positive CEA or $\mathrm{Ca} 19.9$ in the control patients. However, it has been shown that false positive increases in CEA may occur in smokers, and false positive increases in $\mathrm{Ca} 19.9$ have been found in patients with cirrhosis, pancreatitis, or acute cholestasis. ${ }^{27}$ Immunisation against the p53 antigen leading to $\mathrm{p} 53-\mathrm{Ab}$ production may represent an early event in the progression of colorectal cancer. ${ }^{12} 14$ In our series, ${ }^{7}$ patients with non-metastatic colorectal cancer exhibited p53-Abs. It has been shown that p53-Abs can even precede tumour detection. ${ }^{16}$ We noted that they did not appear during disease progression if they were initially absent (data not shown) as it was previously reported. ${ }^{12} 22$

Interestingly, one patient (CC49) with a history of ulcerous colitis displayed high p53-Ab titres. This patient was operated on because of severe dysplasia foci. However, the very focal Dukes' $\mathrm{C}$ colon cancer was missed in preoperative colonoscopy and was only found when the whole resected colon was examined. It has been previously shown that mutations in the p53 gene represent an early marker of neoplastic progression in ulcerative colitis. $^{28}$ However, neoplastic areas are sometimes difficult to identify at endoscopy and can be missed during random biopsies. Thus the clinical use of p53-Ab testing for the early detection of p53 alterations in preneoplastic digestive diseases (ulcerative colitis or Barrett's oesophagus) merits further investigation.

At present, CEA and $\mathrm{Ca} 19.9$ are the most extensively used tumour markers for the management of patients with colorectal cancer. ${ }^{27}$ Thus we thought that it was important to compare $\mathrm{p} 53-\mathrm{Ab}$ testing with both these reference tumour markers. There was a simultaneous increase in CEA and Ca 19.9, and high p $53-\mathrm{Ab}$ titres in only $20 \%$ of patients. Interestingly, $30 \%$ of the patients with normal CEA and $\mathrm{Ca} 19.9$ concentrations exhibited high p53-Ab concentrations. Despite the fact that the sensitivities of CEA and Ca 19.9 (37\% and $28 \%$ respectively) for the diagnosis of colorectal cancer were slightly higher than that of p53-Ab (26\%), our results suggest that CEA measurement and $\mathrm{Ca} 19.9$ and p53-Ab testing may be complementary methods for the management of patients with colorectal cancer.

Variations of p53-Abs during treatment of patients with cancer have been poorly studied. Angelopoulou et $a l^{15}$ reported $\mathrm{p} 53-\mathrm{Ab}$ monitoring in five patients with ovarian cancer and one with breast cancer. In our series, the p53-Ab ratio decreased in 12 out of 14 patients within the first months after surgery, including in those with Dukes' $C$ cancer and hepatic metastasis who only underwent palliative resection. Moreover, we currently reported the results of repeat testing in 12 patietns with p53-Ab. In four of them, the follow up was too short to draw any conclusions. Among the eight patients followed up for 12 months or more, six showed a decrease in p53-Ab concentrations but only three of them returned to a normal $\mathrm{p} 53-\mathrm{Ab}$ ratio. In the three patients, the persistent high $\mathrm{p} 53-\mathrm{Ab}$ ratio without evidence for cancer progression may be due to persistent immunisation against p53 protein. However, a longer follow up is needed to ensure that this phenomenon is not caused by $\underset{\Rightarrow}{\vec{f}}$
undetectable cancer.

The examples of patients $\mathrm{CC} 24$ and $\mathrm{CC} 37$ 을 clearly show that temporal changes in the $\frac{\bar{F}}{\bar{N}}$ p53-Ab ratio can be closely correlated with $\frac{\text { क }}{\sigma}$ disease progression or regression. Rapid but $\stackrel{\square}{\circ}$ incomplete decreases in both patients' p53-Ab ratio, followed by a period of stability at a fairly $\overrightarrow{0}$ high concentration (p53 ratio $>15)$ in one patient, was found before cancer progression. $\vec{\omega}$ In patient CC37, it is possible that hepatice metastases was present at the time of rectal tumour resection but undetectable. Large scale? studies of p53-Ab positive patients with colo- $\omega$ rectal cancer are needed to assess whether I some patterns of change in concentrations ofo p53-Abs indicate either incomplete resection of the tumour or early disease progression.

It has been shown that the presence of circu- $\frac{0}{3}$ lating $\mathrm{p} 53-\mathrm{Abs}$ in patients with breast cancer is an independent factor of poor prognosis. ${ }^{23}$ Thus $\vec{\bullet}$ whether the use of p53-Ab testing might help. physicians to select subgroups of patients with colorectal cancer for preoperative or postoperative adjuvant treatments, needs to beō investigated.

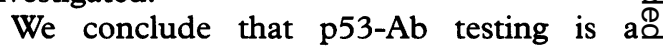
convenient method to detect alterations of the $\overrightarrow{\vec{O}}$ p53 gene in patients with colorectal cancer. 3 Monitoring of p53-Ab may help in the early? diagnosis and treatment of relapse in? asymptomatic patients.

We thank Dr MJ Boudet, D Cherqui, PL Fagniez, JL Hingot, $M$ Julien, and B Tantawi for performing the tumour resections, and D Roche and Y Remvikos for helping in the preparation of the manuscript. This work was supported by grants from the of the manuscript. This work was supported by grants from the $₹$ Association de Recherche sur le Cancer, Ligue Nationale contre Cancer (Comité National)

\section{Addendum}

During the period of revision of this manuscript, $N$ patient CC37 who had high persistant concentrations of p53-Ab after resection of a hepatic metastasis (Fig 3) developed pulmonary meta- $\omega$ stases.

1 Soussi T, Legros Y, Lubin R, Ory K, Schlichtholz B. Multifactorial analysis of p53 alteration in human cancer: a review. Int $\mathcal{F}$ Cancer 1994; 57: 1-9.

2 Hollstein M, Sidransky D, Vogelstein B, Harris C. p53 mutations in human cancers. Science $1991 ; 253$ : 49-53.

Bourdon JC, D'Errico A, Paterlini P, Grigioni W, May E, $\mathbb{D}$ Debuire B. p53 protein accumualtion in european hepatocellular carcinoma is not always dependent on p53 hepatocellular carcinoma is not always dependent on Salmon RJ, Dutrillaux B, Thomas G. Increased p530 protein content of colorectal tumours correlates with poor survival. Br f Cancer 1992; 66: 758-64.

5 Hamelin $R$, Laurent-Puig $P$, Olschwang $S$, Jego $N, \stackrel{?}{?}$ Asselain B, Remvikos Y, et al. Association of p53 mutations with short survival in colorectal cancer. Gastroenterology 1994; 106: 42-8.

6 Thor AD, Moore DH, Edgerton SM, Kawasaki ES, Reihsaus E, Lynch $\mathrm{H}$, et al. Accumulation of p53 tumour suppressor gene protein - an independant marker of prognosis in breast cancers. $\mathcal{F}$ Natl Cancer Inst 1992; 84: 845-55.

7 Starzynska T, Bromley M, Ghosh A, Stern PL. Prognostic significance of p53 overexpression in gastric and colorectal carcinoma. Br $f$ Cancer 1992; 66: 558-62. 
8 Porter PL, Gown AM, Kramp SG, Coltrera MD. Widespread p53 overexpression in human malignant tumours. Am $\mathcal{F}$ Pathol 1992; 140: 145-53.

9 Crawford LV, Pim DC, Bulbrook RD. Detection of antibodies against the cellular protein p 53 in sera from patients with breast cancer. Int $\mathcal{f}$ Cancer 1982; 30: 403-8.

10 Caron de Fromentel C, May-Levin F, Mouriesse $H$, Lemerle J, Chandrasekaran K, May P. Presence of circulating antibodies against cellular protein p53 in a notable proportion of children with B-cell lymphoma. Int notable proportion of childre

11 Davidoff $A M$, Iglehart JD, Marks JR. Immune response to $\mathrm{p} 53$ is dependent upon p53/HSP70 complexes in breast cancers. Proc Natl Acad Sci USA 1992; 89: 3439-42.

12 Schlichtholz B, Legros Y, Gillet D, Gaillard C, Marty M, Lane $\mathrm{D}$, et al. The immune response to p53 in breast cancer patients is directed against immunodominant epitopes unrelated to the mutational hot spot. Cancer Res 1992; 52: 6380-4.

13 Winter SF, Minna JD, Johnson BE, Takahashi T, Gazdar AF, Carbone DP. Development of antibodies against p53 in lung cancer patients appears to be dependent on the type of p53 mutation. Cancer Res 1992; 52: 4168-74.

14 Labrècque $S$, Naor $N$, Thomson $D$, Matlashewski G. Analysis of the anti-p53 antibody response in cancer patients. Cancer Res 1993; 53: 3468-71

15 Angelopoulou K, Diamandis EP, Sutherland DJA, Kellen JA, Bunting PS. Prevalence of serum antibodies against the p53 tumour suppressor gene protein in various against the p53 tumour suppressor gene

16 Lubin R, Zalcman G, Bouchet L, Trédanel J, Legros Y, Cazals D, et al. Serum p53 antibodies as early markers of lung cancer. Nat Med 1995; 1: 701-2.

17 Preudhomme C, Lubin R, Lepelley P, Vanrumbeke $M$, Fenaux P. Detection of serum anti-p 53 antibodies and their correlation with p53 mutations in myelodysplastic syndromes and acute myeloid leukemia. Leukemia 1994; 8: $1589-91$.

18 Wild CP, Ridanpää $M$, Anttila $S$, Lubin $R$, Soussi $T$, Husgafvel-Fursiainen K, Vanino H. p53 antibodies in the sera of lung cancer patients: comparison with p53 mutations in the tumour tissue. Int $\mathcal{F}$ Cancer 1995; 64: 176-81.

19 Legros Y, Lafon C, Soussi T. Linear antigenic sites defined by the B-cell response to human p53 are localized predominantly in the amino and carboxy-termini of the protein. Oncogene 1994; 9: 2071-6.

20 Lubin $R$, Schlichtholz B, Bengoufa D, Zalcman G Trédaniel J, Hirsch A, et al. Analysis of p53 antibodies in patients with various cancers define B-cell epitopes of patients with various cancers define B-cell epitopes of human p53: distribution on primary structure and 5872-6.

21 Schlichtholz B, Trédaniel J, Lubin R, Zalcman G Hirsch A, Soussi T. Analyses of p 53 antibodies in sera of patients with lung carcinoma define immunodominant regions in the 53 protein $B r f$ Cancer $1994 ; 69$; 809-16.

22 Lubin R, Schlichtholz B, Teillaud JL, Garay E, Bussel A Wild CP, Soussi T. p53 antibodies in patients with various types of cancer: identification and characterization. Clin types of cancer: identification

23 Peyrat JP, Bonneterre J, Lubin R, Vanlemmens L, Fournier J, Soussi T. Prognostic significance of circulating p53 antibodies in patients undergoing surgery fo locoregional breast cancer. Lancet 1995; 345: 621-2.

24 Schein PS. Gastrointestinal cancer: a global perspective. In JD Ahlgren, JS Macdonald, eds, Gastrointestinal oncology. Philadelphia: JB Lippincott, 1992: 3-11.

25 Dukes CE. The classification of cancer of the rectum. $f$ Pathol Bacteriol 1932; 35: 323-32.

26 Guinee Jr DG, Travis WD, Trivers GE, De Benedetti VMG Cawley $\mathrm{H}$, Welsh JA, et al. Gender comparisons in human lung cancer: analysis of p 53 mutations, anti-p 53 serum antibodies, and C-erb B-2 expression. Carcinogenesis 1995; 16: 993-1002.

27 Johnson KA, Wolley PV. The role of tumour markers in the management of gastrointestinal malignancies. In: JD Ahlgren, JS Macdonald, eds. Gastrointestinal oncology. Philadelphia: JB Lippincott, 1992: 63-65.

28 Brentnall TA, Crispin DA, Rabinovitch PS, Haggitt RC, Rubin CE, Stevens AC, Burmer GC. Mutations in the p53 gene: an early marker of neoplastic progression in p53 gene: an early marker of neoplastic progression
ulcerative colitis. Gastroenterology 1994; 107: 369-78. 